Ester Trigo Ibáñez

Manuel Francisco Romero Oliva

Universidad de Cádiz

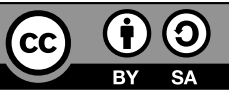

Inmaculada Clotilde Santos Díaz

Universidad de Málaga

\title{
Aproximación al léxico gastronómico dialectal andaluz desde los repertorios de disponibilidad léxica para una propuesta didáctica
}

Palabras clave: disponibilidad léxica, dialectalismo, léxico gastronómico, MCERL, ELE.

\section{Introducción}

Desde los años 70, con el nacimiento del enfoque comunicativo en la enseñanza de lenguas (García Marcos, 2018), se ha prestado atención no solo al conocimiento de los elementos del sistema lingüístico, sino también a cómo su conocimiento capacita a los individuos para establecer relaciones efectivas de comunicación y, por ende, de relación intercultural. En este escenario, uno de los aspectos esenciales para que un hablante o aprendiz pueda demostrar dominio lingüístico es la competencia léxica, definida en el Marco común europeo de referencia para las lenguas (MCERL, Consejo de Europa, 2002: 126131) como «el conocimiento del vocabulario de una lengua y la capacidad para utilizarlo». Como se aprecia, la competencia léxica se considera un apartado dentro de la competencia comunicativa pues una palabra no se considera adquirida/aprendida si el hablante/aprendiz no demuestra que es capaz de desentrañar su entramado cultural (Miquel, 1997) y, además, sabe usarla en diversos contextos: 
La competencia léxica va más allá de las listas exhaustivas y de la competencia gramatical. Además de conseguir y ampliar el bagaje léxico necesario (activo y pasivo), los alumnos tienen que adquirir criterios de uso para cada palabra en relación con el registro, la precisión, las connotaciones, etc., de la situación comunicativa en la que se quiera emplear (Cassany, Luna y Sanz, 1998: 382 ).

En consonancia con esta idea, Castellano-Risco (2018: 12) recuerda que el panorama de investigación relacionado con el vocabulario ha pretendido dar respuesta a «what the term vocabulary knowledge involves, how vocabulary can be measured and how vocabulary is learnt». Estas cuestiones han propiciado diversos debates acerca de qué léxico enseñar y en qué nivel hacerlo (Ainciburu, 2008; 2014; Ávila, 2017a; 2017b; Luque Durán, 2004; Paredes, 2015; Santos Palmou, 2017; Šifrar Kalan, 2016). De estos estudios se desprende que dominar completamente una palabra supone ir más allá que simplemente pronunciarla y escribirla, cuestión íntimamente relacionada con la conciencia fonológica y ortográfica, o conocer su categoría gramatical y su capacidad de combinatoria sintáctica. Es decir: conlleva un conocimiento de sus aspectos semánticos, pragmáticos y sociolingüísticos, en donde se enmarca su valor dialectal, su registro y su uso adecuado dentro de una situación comunicativa dada. De hecho, como indican Lomas y Tusón (2002: 7), al estudiar el léxico de una lengua realizamos un acercamiento a los grupos humanos que la hablan, a sus intereses y finalidades comunicativas pues:

el léxico es, en fin, un marcador y un indicio de las variedades lingüísticas, tanto geográficas o diatópicas (por ejemplo, el léxico específico de una zona geográfica) como sociales o diastráticas (las jergas profesionales o juveniles, los sociolectos asociados a una clase social o al sexo de las personas, etc.) y funcionales o diafásicas (el léxico propio de situaciones formales o informales de comunicación).

Si prestamos atención a las fases propuestas en el MCERL (Consejo de Europa, 2002: 25-26), vemos que, al aprender una lengua, el alumno atraviesa diferentes estadios, iniciándose como usuario básico hasta llegar a ser usuario competente, capaz de interactuar de manera fluida con hablantes nativos, comprendiendo los referentes culturales que se plantean en una situación comunicativa dada. En este viaje formativo, el reto se plantea porque el ascenso internivelar no se consigue simplemente subiendo verticalmente, sino que «esta escala de niveles se asemeja más a un cono tridimensional que se va ensanchando hacia arriba» (Azúar, 2014: 31). 
En el caso del español como lengua extranjera (ELE), esta representación gráfica -cónica, según Azúar (2014) - nos hace evocar a un potencial aprendiz que trata de establecer con éxito una interacción comunicativa con hispanohablantes, pero que no encuentra una total efectividad, pues no es hasta el final de su proceso formativo cuando entrará en contacto con el léxico dialectal (Byram y Fleming, 2001). A este respecto, García y Ferreira (2012: 49) apuntan, explicando las diferencias entre fabada, en español, y feijoada, en portugués, que dominar esta palabra en toda su dimensión supondrá conocer aquellos aspectos culturales que superen lo puramente formal para «saber comportarnos adecuadamente en el contexto de la comida», pero ¿`cómo lograr que el alumnado aprehenda el léxico dialectal? Intentaremos dar respuesta a esta pregunta recurriendo a materiales de disponibilidad léxica y realizando una prospección didáctica basada en el enfoque comunicativo desde el léxico consignado en ellos.

\section{El papel de la disponibilidad léxica en la enseñanza de lenguas}

Los estudios de disponibilidad léxica nacen en Francia, en la década de los 50 del siglo XX, en el marco de la enseñanza de segundas lenguas, pues se pretendía elaborar un vocabulario con el que se pudiera enseñar francés a los habitantes de la antigua Unión Francesa y a los inmigrantes que llegaban a Francia. En una primera fase, la selección del léxico idóneo se realiza a partir de listados de frecuencia, lo que da lugar al léxico básico. Sin embargo, los lingüistas Gougenheim, Michéa, Rivenc y Sauvageot $(1956 ; 1964)$ advierten la escasez de léxico muy necesario en el día a día, sobre todo sustantivos. Por ello, deciden completar los listados recopilando el léxico evocado por los hablantes al referirse a temas de la vida cotidiana, dando así lugar al léxico disponible y a los dieciséis centros de interés que, aunque se han cuestionado en diversas ocasiones (Paredes, 2011), son considerados universales en estos estudios: (01) Partes del cuerpo, (02) La ropa, (03) Partes de la casa (sin los muebles), (04) Los muebles de la casa, (05) Alimentos y bebidas, (06) Objetos colocados en la mesa para la comida, (07) La cocina y sus utensilios, (08) La escuela: muebles y materiales, (o9) Iluminación, calefacción y medios para airear un recinto, (10) La ciudad, (11) El campo, (12) Medios de transporte, (13) Trabajos del campo y del jardín, (14) Los animales, (15) Juegos y distracciones, (16) Profesiones y oficios.

En este sentido, las unidades léxicas usadas en cualquier situación comunicativa constituyen el léxico básico. Sin embargo, las utilizadas solo al abarcar un 
tema concreto conforman el léxico disponible. Ambos métodos son complementarios y nos ofrecen el perfil léxico de una comunidad lingüística (Rodríguez y Muñoz, 2009). Esta idea nos hace pensar en los materiales de disponibilidad léxica como una oportunidad para trabajar con estudiantes extranjeros los elementos culturales que aparecen, pues resulta evidente que la palabra nos hace reflejar nuestra concepción del mundo.

En consecuencia, la disponibilidad léxica pretende identificar el vocabulario evocado por los hablantes - pues está incorporado en su lexicón mental-al pensar en un determinado centro de interés. Con ello se determina «el grado en que las palabras están disponibles en la mente de los hablantes para ser usadas cuando la situación lo requiere» (López Morales, 1994: 62). Esta idea hizo que el lingüista Humberto López Morales impulsara un Proyecto Panhispánico de Disponibilidad Léxica (PPHDL), cuestión que ha propiciado una senda de avance tan prolífica como bien coordinada tanto teórica como metodológicamente (López González, 2014).

A partir de los repertorios de disponibilidad léxica se ha podido avanzar en diversos terrenos estrechamente relacionados con la didáctica de la lengua, entre los que destacamos, en primera instancia, los trabajos que aportan criterios generales para selección del léxico (Bartol, 2010; Ávila, 2017a; 2017b; Paredes, 2015; Santos Díaz, 2017; Santos Palmou, 2017; Šifrar Kalan, 2016); $y$, en segunda, aquellos que fijan su mirada en el léxico diferencial y en el lugar que este ocupa en la didáctica del léxico. Con léxico diferencial nos referimos, por ejemplo, a las creaciones léxicas -o neologismos- (Gallego, 2014; García, 2011; Moliné, 2008; Paredes y Gallego, 2019) o al léxico regional -o dialectalismos- (Ávila, 2017a; 2017b; Galloso y Martín, 2019; González, 1999; Hernández Muñoz, 2009; Prado, 2009; Samper y Hernández Cabrera, 2006; Tabernero, 2008; Trigo, Santos Díaz y Romero, en prensa). Esta trayectoria nos hace considerar a la léxico-estadística como una gran aliada para quienes centran sus investigaciones en la planificación de la enseñanza de lenguas.

Así, partiendo de estas premisas, en nuestro trabajo nos centramos en el léxico regional de Andalucía consignado en los diccionarios de disponibilidad léxica de las ocho provincias (Ahumada, 2006; Ávila, 2006; Bellón, 2011; González; 2002; Mateo, 1998¹; Pastor y Sánchez, 2008; Prado y Galloso,

1 En esta obra no aparecen los repertorios léxicos, sino el estudio sociolingüístico. Las palabras consignadas tanto en este trabajo como en Trigo, Santos Díaz y Romero (en prensa) han sido aportadas por la investigadora almeriense. 
2005 y Trigo, 2011). Habida cuenta de la relación entre la gastronomía y la idiosincrasia de los pueblos, nuestro objetivo es detectar los andalucismos relacionados con el centro de interés alimentos y bebidas para realizar una prospección didáctica centrada en diversas situaciones comunicativas en el ámbito gastronómico. Estas líneas prospectivas, pensadas para un usuario competente, con nivel $\mathrm{C}_{1}-\mathrm{C}_{2}$ de español, podrán resultar de gran ayuda para aquellos estudiantes extranjeros que pretenden disfrutar de una beca Erasmus en Andalucía.

\section{Metodología}

El léxico dialectal que vamos a utilizar para realizar nuestra propuesta didáctica aparece recogido en Trigo, Santos Díaz y Romero (en prensa). Para su selección seguimos un procedimiento análogo al de Prado (2009) al considerarlo un trabajo fundamental en la identificación de dialectalismos en Andalucía. El primer paso fue seleccionar la nómina de posibles dialectalismos registrados en los diccionarios de disponibilidad léxica -compilados según las directrices del PPHDL (López González, 2014) - de las ocho provincias andaluzas y registrarlos en una matriz.

De acuerdo con este procedimiento, para considerar una palabra finalmente como dialectalismo, fue necesaria, en primera instancia, la consulta de diccionarios de uso general -como el DLE, el DUE y el DEA-, en segunda, la de diccionarios regionales -como el Vocabulario Andaluz (Alcalá Venceslada, 1998) o el Tesoro Lexicográfico de las hablas andaluzas (Alvar Ezquerra, 2000) - y, finalmente, acudir a otras fuentes como internet para aclarar las dudas resultantes.

\section{Resultados}

Los resultados que se ofrecen siguen los criterios de los estudios de disponibilidad léxica, pues no pretenden compilar el léxico dialectal, sino el de uso general para identificar voces relacionadas con la cultura de los pueblos. Siguiendo a Trigo, Santos Díaz y Romero (en prensa), el léxico dialectal aparecía en los listados en posiciones inferiores a $100 \mathrm{y}$, por tanto, su índice de disponibilidad léxica solía estar por debajo de o,1. Por esta razón, las palabras recogidas en la tabla 1, obedecen al criterio de selección de la frecuencia de evocación y no al índice de disponibilidad léxica, lo que nos llevó a compilar aquellas palabras que aportaban un mayor calado etnográfico. 


\begin{tabular}{|l|l|c|}
\hline PROVINCIA & VOCABLO & TOTAL \\
\hline Almería & $\begin{array}{l}\text { ajo colorado, brótola, guisillo, gurullo, níspola, olla gitana, présul, } \\
\text { repollo, tapaculo. }\end{array}$ & 9 \\
\hline Cádiz & $\begin{array}{l}\text { ajo caliente, ajo campero, babeta, melva, moscatel, poleá, sargo, } \\
\text { oloroso, tortilla de camarón, mojama. }\end{array}$ & 10 \\
\hline Córdoba & $\begin{array}{l}\text { alpacano, arroz amarillo, bolo, camacha, chanfaina, chupón, codi- } \\
\text { to, corneta, crispín, esponje, garbanzón, gofio, habichuelo, jamón } \\
\text { dulce, mojete, nachi, pale cream, patatas a la brava, patatas a lo } \\
\text { pobre, resoli, rosquillo, telera, vargas. }\end{array}$ & 23 \\
\hline Granada & biscotela, espada, rebollos, remojón, pinchito. & 5 \\
\hline Huelva & frijón careto, gurumelo, pinto, pringada, rabanilla, regañada, robalo. & 7 \\
\hline Jaén & $\begin{array}{l}\text { alpargata, andrajos, caramanchón, chicharrito, chopito, chopo, cho- } \\
\text { ta, chotillo, colleja, gachamiga, gacharrota, habicholón, habicholil- } \\
\text { la, magreta, maimón, ochío, pipirrana, roseta, sabanita, tunera. }\end{array}$ & 20 \\
\hline Málaga & $\begin{array}{l}\text { algarrobo, arenca, cachorreñas, (café) mitad, (café) nube, cala- } \\
\text { marito, calimocho, campero, costillada, cresta, emblanco, gazpa- } \\
\text { chuelo, moraga, pescaíto frito, pintarroja. }\end{array}$ & 15 \\
\hline Sevilla & \begin{tabular}{l} 
meollada, puntillita, regañá. \\
\hline
\end{tabular} & 3 \\
\hline
\end{tabular}

Tabla 1. Léxico dialectal registrado en los diccionarios de disponibilidad léxica de Andalucía

Los resultados obtenidos nos permitirán abordar dos líneas para la planificación de la enseñanza de ELE: por un lado, una primera catalogación de los vocablos en tipos de alimentos - bebidas, verduras y legumbres, carne, pescado, guisos elaborados-; y, por otro lado, una segunda distribución léxica de cara al empleo en situaciones comunicativas cotidianas -desayuno, aperitivo, almuerzo, merienda, cena-.

\subsection{Prospección de los resultados: hacia una propuesta didáctica}

La primera prospección se centra en la distribución del léxico donde, como indica Ávila (2017a), se contemple la necesidad de combinar vocabulario común con vocabulario dialectal. Así, el léxico aportado en nuestra investigación deberá integrarse a los campos semánticos y asociativos de las diferentes planificaciones en el aula de ELE - Vid. Tabla 2-, lo que apoya la idea de las coronas concéntricas (Ávila, 2017a) que ofrece la actualización del léxico en función de determinadas circunstancias temáticas, situacionales y personales, en nuestro caso los tipos de alimentos y las comidas de la jornada de una persona en un contexto real. 


\begin{tabular}{|c|c|c|c|c|c|c|}
\hline $\begin{array}{l}\text { PRO- } \\
\text { VINCIA }\end{array}$ & Bebidas & $\begin{array}{l}\text { Verduras/ } \\
\text { legumbres }\end{array}$ & Carnes & Pescados & $\begin{array}{l}\text { Guisos elabora- } \\
\text { dos }\end{array}$ & $\begin{array}{c}\text { Panade- } \\
\text { ría/ bo- } \\
\text { Ilería }\end{array}$ \\
\hline Almería & & repollo & & $\begin{array}{l}\text { níspola } \\
\text { brótola } \\
\text { présul } \\
\text { tapaculo }\end{array}$ & $\begin{array}{l}\text { ajo colorado } \\
\text { guisillo } \\
\text { gurullo } \\
\text { olla gitana } \\
\end{array}$ & \\
\hline Cádiz & $\begin{array}{c}\text { moscatel } \\
\text { oloroso }\end{array}$ & & & $\begin{array}{l}\text { melva } \\
\text { sargo } \\
\text { tortilla de } \\
\text { camarón }\end{array}$ & $\begin{array}{c}\text { ajo caliente } \\
\text { ajo campero } \\
\text { babeta } \\
\text { poleá } \\
\text { mojama }\end{array}$ & \\
\hline Córdoba & $\begin{array}{l}\text { pale } \\
\text { cream } \\
\text { resoli } \\
\text { vargas }\end{array}$ & $\begin{array}{l}\text { chanfaina } \\
\text { garbanzón } \\
\text { habichuelo }\end{array}$ & $\begin{array}{l}\text { jamón } \\
\text { dulce } \\
\text { codito }\end{array}$ & $\begin{array}{l}\text { crispín } \\
\text { chupón } \\
\text { mojete }\end{array}$ & $\begin{array}{c}\text { alpacano } \\
\text { arroz amarillo } \\
\text { bolo } \\
\text { camacha } \\
\text { gofio } \\
\text { mojete } \\
\text { nachi } \\
\text { patatas a la brava } \\
\text { patatas a lo pobre }\end{array}$ & $\begin{array}{c}\text { corneta } \\
\text { esponje } \\
\text { telera } \\
\text { rosquillo }\end{array}$ \\
\hline Granada & & rebollos & pinchito & espada & & biscotela \\
\hline Huelva & & $\begin{array}{c}\text { frijón } \\
\text { gurumelo }\end{array}$ & careto & $\begin{array}{c}\text { pinto } \\
\text { robalo } \\
\text { rabanilla }\end{array}$ & pringada & regañada \\
\hline Jaén & & $\begin{array}{c}\text { pipirrana } \\
\text { tunera } \\
\text { chicharrito } \\
\text { habicholón } \\
\text { habicholilla }\end{array}$ & $\begin{array}{l}\text { chota } \\
\text { chotillo } \\
\text { colleja } \\
\text { magreta }\end{array}$ & $\begin{array}{l}\text { chopito } \\
\text { chopo } \\
\text { roseta }\end{array}$ & $\begin{array}{c}\text { caramanchón } \\
\text { sabanita } \\
\text { alpargata } \\
\text { andrajos } \\
\text { gachamiga } \\
\text { gacharrota }\end{array}$ & $\begin{array}{l}\text { maimón } \\
\text { ochío }\end{array}$ \\
\hline Málaga & $\begin{array}{l}\text { Calimo- } \\
\text { cho } \\
\text { (café) } \\
\text { mitad } \\
\text { (café) } \\
\text { nube }\end{array}$ & & $\begin{array}{c}\text { costillada } \\
\text { cresta }\end{array}$ & $\begin{array}{c}\text { calamarito } \\
\text { pintarroja }\end{array}$ & $\begin{array}{c}\text { campero } \\
\text { moraga } \\
\text { pescaíto frito } \\
\text { emblanco } \\
\text { gazpachuelo }\end{array}$ & arenca \\
\hline Sevilla & & & & puntillita & meollada & regañá \\
\hline
\end{tabular}

Tabla 2. Léxico dialectal distribuido por tipos de alimentos

La segunda prospección se centra en las situaciones comunicativas cotidianas resultantes de la comida. Siguiendo a Díaz, Martínez y Redó (2011), el desarrollo de los contenidos lingüísticos para ELE en sus niveles $\mathrm{C}_{1}-\mathrm{C}_{2}$ se concreta en cuestiones sociopragmáticas vinculadas a una gramática discursiva que se centra en la adecuación al contexto, la coherencia del contenido y la cohesión 
textual. En este sentido, nos encontramos con el contexto situacional en el que se precisan «las variaciones en el uso monogal y dialógico. Registro: léxicos restringidos y especializados (escritos) y fraseología (oral)» (Díaz, Martínez y Redó, 2011: 141). De esta forma, se establecen transacciones prácticas en las que los aprendices deberán enfrentarse a situaciones comunicativas cotidianas entre las que se encuentran actos sociales como comer fuera o cocinar en casa -en nuestro caso, comidas de una jornada, Vid. Tabla $3-$, y entender toda clase de anuncios de restauración.

\begin{tabular}{|l|c|c|c|c|c|}
\hline PROVINCIA & Desayuno & Aperitivo & Almuerzo & Merienda & Cena \\
\hline Almería & & & ajo colorado & & níspola \\
brótola \\
présul \\
brótola \\
tapaculo
\end{tabular}




\begin{tabular}{|c|c|c|c|c|c|}
\hline PROVINCIA & Desayuno & Aperitivo & Almuerzo & Merienda & Cena \\
\hline Granada & biscotela & & $\begin{array}{l}\text { espada } \\
\text { rebollos } \\
\text { remojón } \\
\text { pinchito }\end{array}$ & biscotela & $\begin{array}{l}\text { espada } \\
\text { rebollos } \\
\text { pinchito }\end{array}$ \\
\hline Huelva & & regañada & $\begin{array}{c}\text { frijón } \\
\text { careto } \\
\text { gurumelo } \\
\text { pinto } \\
\text { pringada } \\
\text { rabanilla } \\
\text { regañada } \\
\text { robalo }\end{array}$ & & $\begin{array}{l}\text { gurumelo } \\
\text { pinto } \\
\text { rabanilla } \\
\text { regañada } \\
\text { robalo }\end{array}$ \\
\hline Jaén & maimón & ochío & $\begin{array}{c}\text { alpargata } \\
\text { andrajos } \\
\text { caramanchón } \\
\text { chicharrito } \\
\text { chopito } \\
\text { chopo } \\
\text { chota } \\
\text { chotillo } \\
\text { colleja } \\
\text { gachamiga } \\
\text { gacharrota } \\
\text { habicholón } \\
\text { habicholilla } \\
\text { magreta } \\
\text { pipirrana } \\
\text { roseta } \\
\text { sabanita } \\
\text { tunera }\end{array}$ & maimón & $\begin{array}{l}\text { caramanchón } \\
\text { chopito } \\
\text { chopo } \\
\text { pipirrana } \\
\text { roseta } \\
\text { sabanita } \\
\text { tunera }\end{array}$ \\
\hline Málaga & $\begin{array}{l}\text { (café) mitad } \\
\text { (café) nube }\end{array}$ & $\begin{array}{c}\text { arenca } \\
\text { calimocho }\end{array}$ & $\begin{array}{l}\text { algarrobo } \\
\text { arenca } \\
\text { cachorreñas } \\
\text { calamarito } \\
\text { calimocho } \\
\text { campero } \\
\text { costillada } \\
\text { cresta } \\
\text { emblanco } \\
\text { gazpachuelo } \\
\text { moraga } \\
\text { pescaíto frito } \\
\text { pintarroja }\end{array}$ & $\begin{array}{l}\text { (café) mitad } \\
\text { (café) nube }\end{array}$ & $\begin{array}{c}\text { calamarito } \\
\text { pintarroja } \\
\text { campero } \\
\text { moraga } \\
\text { pescaíto frito }\end{array}$ \\
\hline Sevilla & & regañá & $\begin{array}{c}\text { meollada } \\
\text { puntillita } \\
\text { regañá }\end{array}$ & & puntillita \\
\hline
\end{tabular}

Tabla 3. Léxico dialectal distribuido por situaciones comunicativas de la comida por provincias 


\section{Conclusiones}

En nuestro trabajo hemos aunado una doble perspectiva en la enseñanza de ELE: la visión comunicativa del lenguaje, que se concreta en las situaciones comunicativas cotidianas que un hablante puede experimentar en su vida (ámbitos público y de lugares, según el MCERL: restaurantes, bares y hoteles, agrupados en objetos, como son comidas, bebidas y tapas); y una visión de la enseñanza de la gramática vinculada a situaciones comunicativas para mejorar el comportamiento lingüístico de los hablantes, en la que la disponibilidad léxica nos ofrece la posibilidad de vincular elementos lingüísticos empleados por los usuarios desde la evocación en contextos cotidianos y que se deben incorporar a la planificación didáctica para la enseñanza del español. Desde esta óptica, «las formas que mostraron resistencia a la convergencia léxica son las originariamente más difundidas en los campos de experiencia estrechamente relacionados con la vida local o regional y las que presentan una composición morfológica más elemental y, siempre, análoga a otras formas del español general no técnico ni especializado» (Ávila, 2017b: 552).

Como se ha puesto de manifiesto, los repertorios de disponibilidad léxica se convierten en una valiosa fuente para establecer una adecuada planificación en la enseñanza de lenguas, pues es precisamente esta parcela la que da cuenta de cómo una comunidad de habla concibe su realidad más inmediata. Así, consideramos que este punto de partida puede arrojar $-\mathrm{y}$, de hecho, arrojaimportantes claves para regalar este mundo, perteneciente en principio a los hablantes nativos, a quienes quieran aproximarse a una lengua y a su cultura, ya sean estudiantes que aprenden la lengua extranjera en un contexto de no exposición, ya sean estudiantes que, al disfrutar de becas de movilidad -como puede ser la Erasmus-, se sumergen en el contexto donde se aprende la lengua.

\section{Bibliografía}

Ahumada, I. (2006): El léxico disponible de los estudiantes preuniversitarios de la provincia de Jaén. Jaén: Universidad de Jaén e Intercambio.

Ainciburu, M. C. (2008): «La enseñanza del léxico en las lenguas extranjeras. ¿Qué palabras hay que enseñar?». En: III Jornadas de Español como Lengua Extranjera, I Congreso Internacional de Enseñanza e Investigación en ELSE, 2123 de mayo de 2008. Argentina: Universidad Nacional de Córdoba.

Ainciburu, M. C. (2014): «El léxico en L2: la adquisición del vocabulario y sus mitos ¿Existe el vocabulario rentable?». Signos ELE, 8, 1-18. 
Alcalá Venceslada, A. (1998): Vocabulario Andaluz, edición Facsímil de la impresa por la Real Academia Española en 1951. Estudio preliminar y edición por Ignacio Ahumada. Jaén: Universidad-Caja Sur.

Alvar Ezquerra, M. (2000): El Tesoro Léxico de las Hablas Andaluzas. Madrid: Arco/Libros.

Ávila, A. M. (2006): Léxico disponible de los estudiantes preuniversitarios malagueños. Málaga: Universidad de Málaga.

Ávila, A. M. (2017a): «La utilidad del vocabulario dialectal en el aula de lenguas extranjeras. Propuesta de selección léxica basada en coronas concéntricas». Marco ELE, 25, 1-21.

Ávila, A. M. (2017b): «Entre limonetis y malaguitas: Estudio del léxico divergente de proximidad. Nuevos datos del Proyecto CONVERLEX-Málaga». Hispania, 100(4), 538-553.

Azúar, C. (2014): «La enseñanza del español coloquial conversacional a través del cine en el aula de ELE intermedio». Tejuelo, 20, 27-56.

Bartol, J. A. (2010): «Disponibilidad léxica y selección de vocabulario». En: Rosa María Castañer, Vicente Lagüéns (coords.), De moneda nunca usada: Estudios dedicados a José $M^{a}$ Enguita Utrilla. Zaragoza: Institución Fernando el Católico, 85-107.

Bellón, J. J. (2011): Léxico disponible de la provincia de Córdoba. Córdoba: Universidad de Córdoba.

Byram, M., Fleming, M. (2001): Perspectivas interculturales en el aprendizaje de idiomas. Madrid: Cambridge University Press.

Cassany, D., Luna, M., Sanz, G. (1998): Enseñar lengua. Barcelona: Graó.

Castellano-Risco, I. (2018): «Vocabulary learning strategies: their relation to learning success». Lenguaje y textos, 48, 11-20.

Consejo de Europa (2002): Marco común europeo de referencia para las lenguas: aprendizaje, enseñanza, evaluación. Madrid: Instituto Cervantes, Ministerio de Educación, Cultura y Deporte-Anaya.

Díaz, L., Martínez, R., Redó, J. A. (2011): Guía de contenidos lingüísticos por niveles del español según el Marco Común Europeo de Referencia para ELE. Barcelona: Octaedro.

Gallego, D. J. (2014): Léxico disponible de estudiantes de español como lengua extranjera en la Comunidad de Madrid. Tesis Doctoral. Madrid: Universidad de Alcalá. 
Galloso, M. V., Martín, M. (2019): «La disponibilidad léxica en el Diccionario de onubensismos para la enseñanza de ELE». Ogigia. Revista electrónica de estudios bispánicos, 25, 211-231.

García, F. (2011): «La creatividad léxica a través de los recursos morfológicos del léxico disponible del español de Galicia». En: Belén López Meirama (ed.), Estudios sobre disponibilidad léxica en el español de Galicia. Santiago de Compostela: Universidad de Santiago de Compostela, 217-266.

García Marcos, F. E. (2018): La trastienda de la enseñanza de lenguas extranjeras. Málaga: Comares.

García, J. M., Ferreira, H. J. (2012): Dudas y obstáculos en el aprendizaje de ELE: el léxico. Brasilia, DF: Consejería de Educación de la Embajada de España.

González, A. E. (1999): «Andalucismos del léxico disponible de la provincia de Cádiz». TAVIRA, 16, 181-193.

González, A. E. (2002): La disponibilidad léxica de los alumnos preuniversitarios de la provincia de Cádiz. Cádiz: Universidad de Cádiz.

Gougenheim, G., Michéa, R., Rivenc, P., Sauvageot, A. (1956): L'élaboration du français élémentaire (I Degré). Étude sur l'établissement d'un vocabulaire et d'une grammaire de base. Paris: Didier.

Gougenheim, G., Michéa, R., Rivenc, P., Sauvageot, A. (1964): L'élaboration du français fondamental (I Degrée). Étude sur l'établissement d'un vocabulaire et d'une grammaire de base. Paris: Didier.

Hernández Muñoz, N. (2009): «Aspectos sociolectales del léxico dialectal». Spanish in context, 6(2), 224-248.

Lomas, C., Tusón, A. (2002): «El léxico». Textos. Didáctica de la lengua y la literatura, 31, 7-10.

López González, A. M. (2014): Disponibilidad léxica. Teoría, método y análisis. Lodz: Universidad de Lodz.

López Morales, H. (1994): Enseñanza de la lengua materna. Lingüística para maestros del español. Madrid: Playor.

Luque Durán, J. (2004): Aspectos universales y particulares del léxico de las lenguas del mundo. Granada: Impedisur.

Mateo, M. ${ }^{a}$ V. (1998): Disponibilidad léxica en el COU Almeriense: Estudio de estratificación social. Almería: Universidad de Almería.

Miquel, L. (1997): «Lengua y cultura desde una perspectiva pragmática». Revista Frecuencia-L, 5, 2-4. 
Moliné, A. B. (2008): «Creación léxica en el vocabulario de los jóvenes aragoneses: aspectos morfológicos». En: María Luisa Arnal (ed.), Estudios sobre disponibilidad léxica en los jóvenes aragoneses. Zaragoza: Institución Fernando el Católico/Excma. Diputación de Zaragoza, 163-194.

Moliner, M. (2007): Diccionario de uso del español. Madrid: Gredos, $3^{\mathrm{a}}$ ed.

Paredes, F. (2014): «A vueltas con la selección de 'centros de interés' en los estudios de disponibilidad léxica: para una propuesta renovadora a propósito de la disponibilidad léxica en ELE». Revista Nebrija de Lingüística Aplicada, 16, 54-59.

Paredes, F. (2015): «Disponibilidad Léxica y enseñanza de ELE: el léxico disponible como fuente curricular y como recurso en el aula». Linred. Monográfico $V$ Jornadas de Lengua y comunicación: 'Léxico, enseñanza y comunicación', 1-32.

Paredes, F., Gallego, D. (2019): «Procedimientos neológicos en el léxico disponible de español como lengua materna y como lengua extranjera». Ogigia. Revista electrónica de estudios bispánicos, 25, 109-138.

Pastor, M. A., Sánchez, F. J. (2008). El léxico disponible de Granada y su provincia. Granada: Universidad de Granada.

Prado, J. (2009): «Dialectalismos en el léxico disponible de Huelva en relación con el centro de interés 'alimentos y bebidas'». En: María Victoria Camacho, Juan José Rodríguez, Juana Santana (coords.), Estudios de lengua española: descripción, variación y uso. Homenaje a Humberto López Morales. Madrid: Iberoamericana-Vervuert, 567-598.

Prado, J., Galloso, M. V. (2005): El léxico disponible de Huelva. Nivel preuniversitario. Huelva: Universidad de Huelva.

Real Academia Española (2001): Diccionario de la lengua española (22. ${ }^{a}$ ed.). Madrid: Editorial Espasa Calpe: http://rae.es/rae.html (25-06-2019).

Rodríguez, F., Muñoz, I. O. (2009): «De la disponibilidad a la didáctica léxica». Tejuelo, 4, 8-18.

Samper, J. A., Hernández Cabrera, C. E. (2006): «Densidad de dialectalismos y condicionantes sociales en el léxico disponible de Gran Canaria». En: Mercedes Sedano, Adriana Bolívar, Martha Shiro (eds.), Haciendo lingüística. Homenaje a Paola Bentivoglio. Caracas: Universidad Central de Venezuela, $537-553$.

Santos Díaz, I. C. (2017): «Selección del léxico disponible: propuesta metodológica con fines didácticos». Porta Linguarum Revista internacional de didáctica de las lenguas extranjeras, 27, 122-139. 
Santos Palmou, X. (2017): Métodos de selección léxica aplicados a la enseñanza. El vocabulario fundamental del español. Tesis doctoral inédita. Salamanca: Universidad de Salamanca.

Seco, M., Andrés, O., Ramos, G. (1999): Diccionario del español actual, 2 vols., Madrid: Aguilar.

Šifrar Kalan, M. (2016): «La universalidad de los prototipos semánticos en el léxico disponible del español». Verba Hispanica, 24, 147-165.

Tabernero, C. (2008): El léxico disponible como fuente de aproximación al estudio de regionalismos. En: Inés Olza, Manuel Casado, Ramón González Ruiz (eds.), Actas del XXXVII Simposio Internacional de la Sociedad Española de Linguíistica (SEL). Pamplona: Servicio de Publicaciones de la Universidad de Navarra, 811-824.

Trigo, E. (2011): Dialectología y cultura. El léxico disponible de los preuniversitarios sevillanos. Valencia: Aduana Vieja.

Trigo, E., Santos Díaz, I. C., Romero, M. F. (2021, en prensa): «Recopilación del léxico disponible dialectal en Andalucía sobre alimentos desde el análisis sociolingüístico de la muestra sevillana», Revista Española de Lingüística Aplicada, 34(1). 
Ester Trigo Ibáñez

Manuel Francisco Romero Oliva

University of Cádiz

Inmaculada Clotilde Santos Díaz

University of Málaga

\section{Approach to the Andalusian dialect gastronomic lexicon from the repertoires of lexical availability for a didactic proposal}

Key words: lexical availability, dialectalism, gastronomic lexicon, CEFRL, SFL.

The analysis of the dialectal words of a speaking community is transcendental in multiple disciplines, specially Language Teaching. The objectives of this paper are, on the one hand, to collect the dialectalisms of the center of interest «Food and drinks» present in the dictionaries of lexical availability of the eight Andalusian provinces and, on the other hand, to make a didactic proposal for students of SFL, level $\mathrm{C}_{1}-\mathrm{C}_{2}$ of the CEFRL. For the collection of data, the lexical availability materials of the studies carried out in Andalusia have been used. 129 words have been registered and distributed provincially taking into account two criteria: the temporal one, which has a relationship with foods that one can eat through the different moments of a day dedicated to the alimentation -breakfast, lunch and dinner-; and the typological one, with is related to the type of food -drinks, vegetables/legumes, meat, fish, cooked food and sweets and bread- with the lexical repertory obtained it will be possible to design didactic sequences under the communicative vision of language, grouped in communicative situations of daily life than one can experiment in his life (public environments and places, according to CEFRL: restaurants, bars and hotels, concreted in objects, like foods, drinks and tapas) and the teaching of grammar, which takes as reference the structure of language and communication, in our case, lexical selection. 
Ester Trigo Ibáñez

Manuel Francisco Romero Oliva

Univerza v Cádizu

Inmaculada Clotilde Santos Díaz

Univerza v Málagi

\section{Pristop $k$ andaluzijskemu narečnemu gastronomskemu besedišču $z$ vidika naborov leksikalne razpoložljivosti $z$ namenom izdelave didaktičnega predloga}

Ključne besede: leksikalna razpoložljivost, dialektizem, gastronomsko besedišče, SEJO, španščina kot tuji jezik.

Analiza narečnih prvin $\mathrm{v}$ jezikovni skupnosti je bistvenega pomena $\mathrm{v}$ mnogih disciplinah, še posebej pa pri poučevanju jezikov. $V$ prispevku se namerava raziskati didaktične razsežnosti dialektizmov s semantičnega polja brana in pijača, ki jih najdemo v slovarjih leksikalne razpoložljivosti vseh osmih andaluzijskih provinc, za učence španščine kot tujega jezika na ravni $\mathrm{C}_{1}-\mathrm{C}_{2}$ po Skupnem evropskem jezikovnem okviru (SEJO). Podatki so zbrani na podlagi gradiv iz raziskav leksikalne razpoložljivosti v Andaluziji. Nabor obsega 129 besed, ki so po provincah razdeljene $\mathrm{v}$ skladu $\mathrm{z}$ dvema meriloma: časovnim, po katerem se živila delijo glede na čas, ki ga namenjamo prehranjevanju -zajtrk, kosilo, malica in večerja-; in tipološkim, ki se nanaša na vrsto živila -pijača, zelenjava/stročnice, meso, ribe, enolončnice in kuhane jedi ter slaščičarski/pekarski izdelki-. Na osnovi pridobljenega nabora besedišča se bodo lahko oblikovale didaktične aktivnosti, in sicer $z$ dveh vidikov: $s$ sporazumevalnega vidika jezika, ki se udejanja v vsakdanjih sporočanjskih okoliščinah (javna mesta po SEJO: restavracije, bari in hoteli, razvrščena glede na predmete, kot so hrana, pijača in tapas); in s pragmatičnega vidika slovnice, ki je osnovan na jezikovni zgradbi in sporazumevanju, v našem primeru pa usmerjen predvsem v izbiro besedišča. 